\title{
OVERVIEW OF RISK-ESTIMATION TOOLS FOR PRIMARY PREVENTION OF CARDIOVASCULAR DISEASES IN EUROPEAN POPULATIONS
}

\author{
Vitali Gorenoi, Anja Hagen \\ Institute for Epidemiology, Social Medicine and Health Systems Research, Hannover Medical School, Hannover, Germany
}

\begin{abstract}
SUMMARY
To identify persons with a high risk for cardiovascular diseases (CVD) special tools (scores, charts, graphics or computer programs) for CVD-risk assessment based on levels of the certain risk factors have been constructed. The applicability of these instruments depends on the derivation cohorts, considered risk factors and endpoints, applied statistical methods as well as used formats.

The review addresses the risk-estimation tools for primary prevention of CVD potentially relevant for European populations. The risk-estimation tools were identified using two previously published systematic reviews as well as conducting a literature search in MEDLINE and a manual search. Only instruments were considered which were derived from cohorts of at least 1,000 participants of one gender without pre-existing CVD, enable risk assessment for a period of at least 5 years, were designed for an age-range of at least 25 years and published after the year 2000.

A number of risk-estimation tools for CVD derived from single European, several European and from non-European cohorts were identified. From a clinical perspective, seem to be preferable instruments for risk of CVD contemporary developed for the population of interest, which use easily accessible measures and show a high discriminating ability. Instruments, restricting risk-estimation to certain cardiovascular events, recalibrated high-accuracy tools or tools derived from European populations with similar risk factors distribution and CVD-incidence are the second choice. In younger people, calculating the relative risk or cardiovascular age equivalence measures may be of more benefit.
\end{abstract}

Key words: cardiovascular disease, risk assessment, prevention, review, statistical models

Address for correspondence: V. Gorenoi, Institute for Epidemiology, Social Medicine and Health Systems Research, Hannover Medical School, Carl-Neuberg-Str. 1, 30625 Hannover, Germany. E-mail: gorenoi.vitali@mh-hannover.de

\section{INTRODUCTION}

\section{The Importance of Tools for Risk Estimation of Car- diovascular Disease for European Populations}

The burden of cardiovascular diseases (CVD) is thought to be reduced when applying preventive interventions which modify CVD-associated risk factors (1). These interventions may be provided to general population or, if their use is associated with potential side-effects and/or high costs, restricted to individuals with a high risk of CVD (2). To identify high-risk individuals special tools for CVD-risk estimation have been constructed.

Using the levels of certain risk factors the CVD risk-estimation tools enable the assessment of an individual's risk for the development of cardiovascular events such as myocardial infarction (MI), stroke or different forms of CVD (also imply symptoms like angina pectoris). Primary, a risk-estimation tool is constructed as an equation with a specific regression coefficient for each included risk factor, based on a statistical analysis of data from a population of a certain region, the so-called derivation cohort (3). The derived regression equation can be further transformed into a score, chart, graphic or used for a computer program.

Risk-estimation tools may assess not only the individual's absolute risk within several years or in life (lifetime-risk), but also the risk in relation to that of a low-risk person of the same gender and age (relative risk) or the age of the person with the same risk but ideal risk profile (Cardiovascular Age, Heart Age, etc.).

The recently published systematic and narrative reviews addressing CVD risk-estimation tools (4-8) have not primarily focused on their applicability for the European populations. Moreover, the systematic reviews $(6,7)$ are not up-to-date, whereas the narratives reviews $(4,5,8)$ consider only selected instruments, e.g. recommended by the U.S. guidelines on CVD prevention. The presented review addresses the risk-estimation tools for primary prevention of CVD potentially relevant for European populations and provides an important addition to the previously published methodically-focused articles $(4,9,10)$.

\section{MATERIALS AND METHODS}

\section{Requirements for a Good Risk-estimation Tool}

The applicability of risk-estimation tools depends on the derivation cohorts, considered risk factors and endpoints, applied statistical methods as well as used formats. These aspects were discussed in detail previously $(4,9,10)$ and will be only briefly summarised here.

The derivation cohort should be representative of the general population of the region. Involving highly selected groups, such as employees or patients of medical practices, can bias the risk esti- 
mates. The cohort-size and the number of events in the follow-up should be both high enough to provide a precise event prediction.

The selection of the risk factors should be based on statistical data analysis of preselected potential relevant variables. Most risk-estimation tools are based on the conventional risk factors: age, gender, smoking, blood pressure, and cholesterol (total and its high-density or low-density fractions). Many tools include additional risk factors such as diabetes mellitus (DM), family history of CVD; simplified tools use body height and weight instead of laboratory tests. The measurement of a risk factor should be easy, well-standardised and intended to be carried out for the entire derivation cohort.

The standardization also plays an important role in the selection of the endpoints. The more easily standardised endpoints comprise less subjective or "hard" events (MI, stroke, death), especially fatal ones. However, the inclusion into the composite cardiovascular endpoints of more subjective or "soft" outcomes (angina pectoris, heart failure, etc.) is favourable from a clinical perspective.

Preferable statistical methods for deriving risk-estimation tools are Cox and Weibull regressions as they enable the risk assessment for different follow-up times or if certain values are missing.

The format of a risk-estimation tool (score, chart, graphic, online calculator, etc.) plays an important role for its efficacy and practicability. The integration of a risk assessment into the medical computer software is aimed to enable a time-saving automatic risk calculation.

\section{Performance Criteria for Risk-estimation Tools}

Although a number of risk-estimation tools were constructed world-wide, their applicability to populations other than the derivation cohort may be limited due to differences in genetics, life-style, environment, etc. $(4,10)$. The commonly used statistical parameters to evaluate the predictive performance of instruments are: calibration, discrimination and net reclassification index. The performance of the instrument can be assessed over risk-estimation on the derivation cohort (internal validation) or on another population (external validation).

Calibration is measured as a ratio between the numbers of predicted and observed events. Good calibration means that the predicted risk is neither too high nor too low referred to the observed risk, with the best achievable value being 1.0 (11). Due to changes over time and regional differences in CVD-risk a risk-estimation tool often overestimates or underestimates the event rate when applied either many years after construction or to populations of geographic regions other than the derivation cohort. In order to overcome this problem the prediction equation can be recalibrated, using the mean values for risk factors and the event rates of the population of interest (12).

Discrimination refers to the ability of a risk-estimation tool to differentiate between individuals in whom an event will occur or not. It is mainly calculated as the area under the receiveroperating-characteristic (AUROC) curve (11). An AUROC of 0.5 indicates that the event prediction is not better than chance alone, whereas an AUROC of 1.0 indicates a correct prediction for all persons.

Recently, the net reclassification index is introduced to compare the performance of risk-estimation tools in terms of classifying individuals into appropriate risk categories (8). This parameter is generally used to appraise the incorporation of new risk factors in the equation (4).

\section{Data Search and Selection}

Initially, risk-estimation tools potentially relevant for this review were identified using two previously published systematic reviews, literature search up to July 2004 or April 2008, respectively $(6,7)$. Additionally, a literature search was conducted in MEDLINE using the terms 'risk', 'predict', 'score', 'chart', 'table', 'engine', 'equation' and the Medical Subject Terms 'risk assessment' and 'cardiovascular disease' in March 2013. Finally, a manual search was performed in the reference lists of relevant articles as well as on the relevant websites.

The review addresses exclusively risk-estimation tools for asymptomatic patients without pre-existing CVD. Tools focusing on specific risk groups, such as patients with DM or with arterial hypertension, were excluded. The presentation of formulae or $\beta$ coefficients, charts, point scores, or online calculators that were derived from a prospective cohort study was considered as a publication of a risk-estimation tool.

In order to base the review on statistically powerful and clinically relevant prognostic models, only risk-estimation tools were considered that were derived from cohorts of at least 1,000 participants of one gender, enable risk assessment for a period of at least 5 years and are designed for an age range of at least 25 years. Because of secular change in the CVD-risk (4) instruments published before the year 2000 were generally not included in this review.

The identified risk-estimation tools were divided into tools derived from single European, several European and from nonEuropean countries (Table 1). The acronyms of the identified risk-estimation tools were considered as proper names and not spelled out in the description of the instruments.

\section{RESULTS}

\section{Risk-estimation Tools Derived from Cohorts of Single European Countries}

\section{PROCAM}

The German PROCAM score can be referred to as the first internationally known European risk-estimation tool. The first version was developed as a point score for estimating the risk of a coronary event within 10 years and was published in 2002 (13). The new version of the PROCAM score released in 2007 is based on the data from almost 27,000 employees aged 20-78 years, approximately one third women (14). Beyond conventional risk factors data on triglycerides, DM and a family history of MI were used as prognostic variables. An online version of the score is provided as PROCAM Health Check (15) and calculate also the relative risk of a coronary event. The website also offers the PROCAM Quick Check (15) which enables an interactive estimation of the risk for coronary event using the personal data on body height, weight and antihypertensive treatment instead of laboratory parameters.

The publication on the new version of the PROCAM score also presents a point score for the risk of an ischaemic cerebral event 


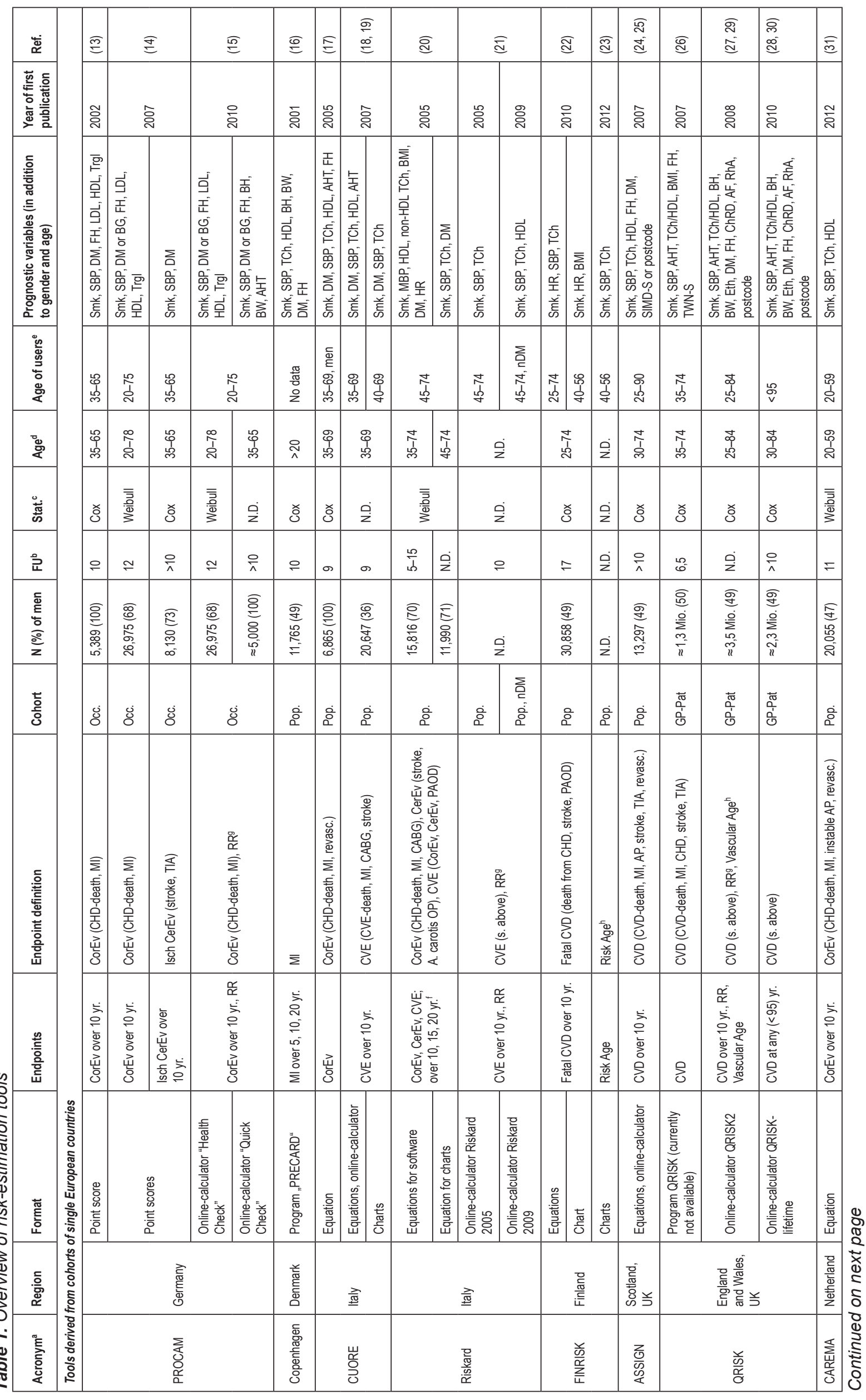




\begin{tabular}{|c|c|c|c|c|c|c|c|c|c|c|c|c|c|c|c|c|c|c|c|c|}
\hline 宓 & & $\begin{array}{l}\text { m } \\
\text { 心్లై }\end{array}$ & & 盆 & 䓃 & 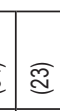 & 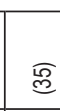 & 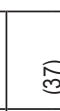 & & & 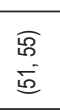 & 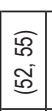 & $\begin{array}{l}\text { 点 } \\
\text { 品 }\end{array}$ & $\begin{array}{l}\text { 豆 } \\
\text { 通 }\end{array}$ & & & 盒 & & $\begin{array}{l}\widehat{\sigma} \\
\overline{0} \\
\bar{c}\end{array}$ & 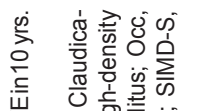 \\
\hline 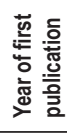 & & @্ & & 음 & 음 & 就 & 总 & ڤે & & & $\stackrel{\text { 咀 }}{ }$ & 商 & : & ڤ్ & & 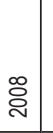 & 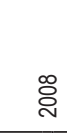 & & : & 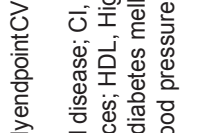 \\
\hline 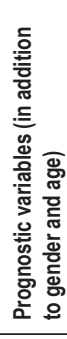 & & 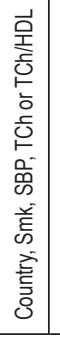 & 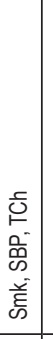 & 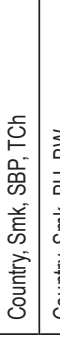 & 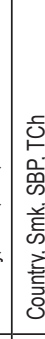 & 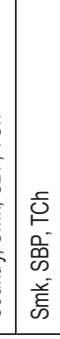 & 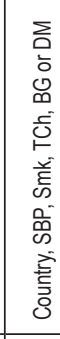 & 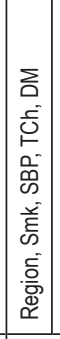 & 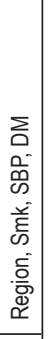 & & 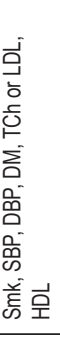 & 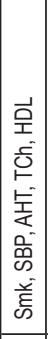 & 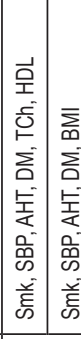 & 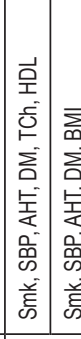 & 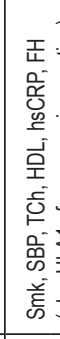 & & 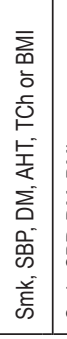 & 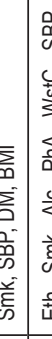 & 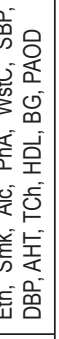 & 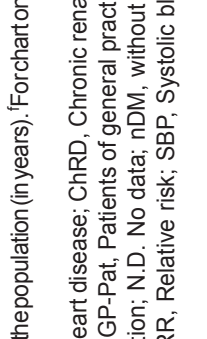 \\
\hline 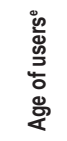 & & 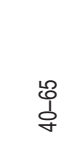 & & 員 & & 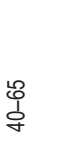 & 离 & î & & & 壳 & $\begin{array}{l}5 \\
0 \\
o \\
o \\
1 \\
\text { d. } \\
0\end{array}$ & $\begin{array}{l}\text { 志 } \\
\text { 今. }\end{array}$ & 㝠 & בे & & 志 & & 윳 & 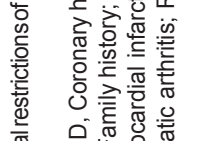 \\
\hline 嵒 & & $\begin{array}{l}\text { d. } \\
\stackrel{\alpha}{\alpha}\end{array}$ & & $\begin{array}{l}\text { o. } \\
\text { d. }\end{array}$ & & @ & 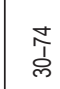 & $\frac{0}{z}$ & & & 壳 & $\frac{i}{z}$ & 㽦 & 䁶 & ه్ & & 壱 & & 亲 & \\
\hline 迡 & & $\begin{array}{l}\overline{\overline{\bar{g}}} \\
\frac{\bar{m}}{3}\end{array}$ & & 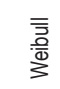 & & 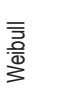 & ১্ & z & & & ठ઼ & ơ & ơ & ठ઼ & ò & & ১̊ & & ઠ̊ & 离 \\
\hline 론 & & $\stackrel{m}{9}$ & & $\stackrel{m}{=}$ & & $\stackrel{m}{g}$ & 움 & z & & & $\stackrel{\wedge}{\wedge}$ & ì & $\stackrel{\sim}{v}$ & $\approx$ & 웅 & & $\stackrel{\lambda}{\wedge}$ & & ه & \\
\hline $\begin{array}{l}\frac{\overline{\mathrm{J}}}{\mathrm{E}} \\
\frac{\mathrm{c}}{\mathrm{O}} \\
\frac{\mathrm{O}}{\mathrm{O}}\end{array}$ & & 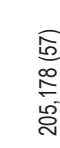 & & 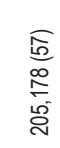 & & 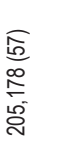 & 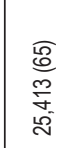 & $\frac{0}{z}$ & & & 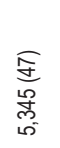 & i & 誉 & 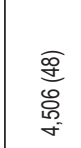 & & & $\begin{array}{l}\frac{0}{9} \\
\frac{0}{0} \\
\frac{0}{0}\end{array}$ & & 虞 & 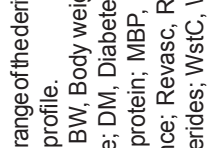 \\
\hline 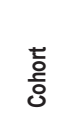 & & 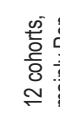 & & 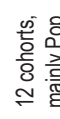 & & 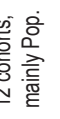 & 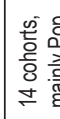 & $\frac{\bar{d}}{\frac{d}{0}}$ & & & 용 & 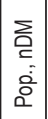 & оㅇ & 옹 & & & 응 & & 응 & $\bar{c}$ \\
\hline 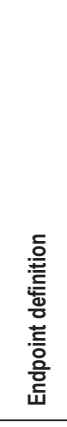 & & 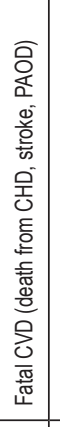 & 总 & 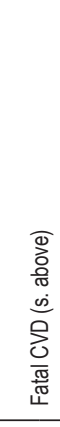 & 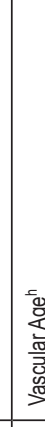 & 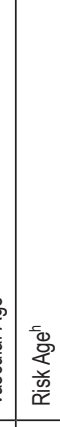 & 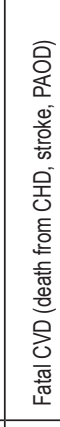 & 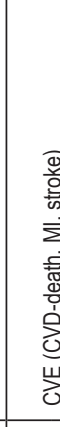 & & & 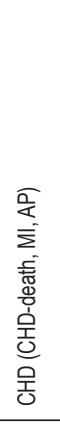 & 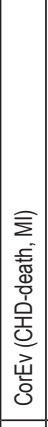 & 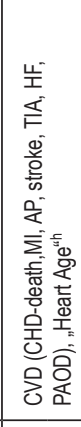 & 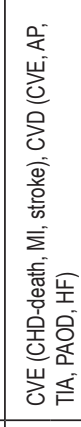 & 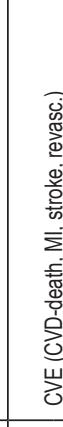 & & 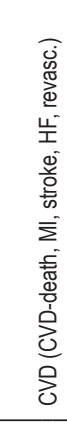 & & 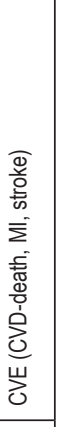 & 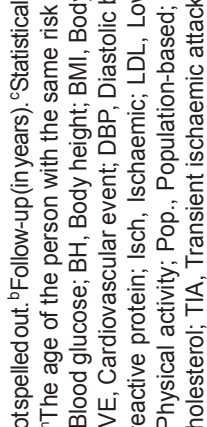 \\
\hline $\begin{array}{l}\text { 号 } \\
\text { 흘 } \\
\text { 해 }\end{array}$ & & 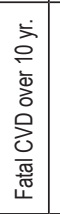 & $\frac{\propto x}{x}$ & 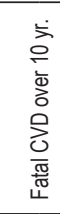 & 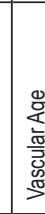 & 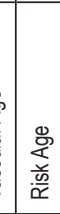 & 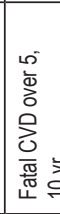 & 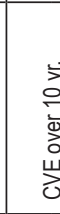 & & & 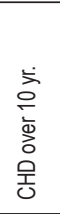 & 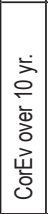 & 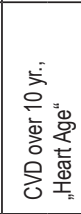 & 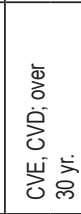 & 5 & & 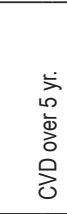 & & 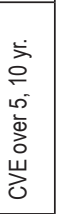 & \\
\hline $\begin{array}{l}\text { 䓂 } \\
\text { 产 } \\
\end{array}$ & 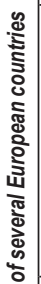 & 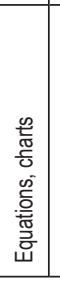 & $\begin{array}{l}\frac{\mathrm{t}}{\mathrm{w}} \\
\frac{\mathrm{w}}{\mathrm{s}} \\
\end{array}$ & 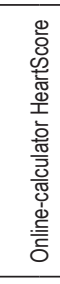 & 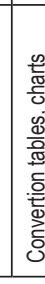 & 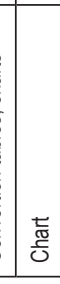 & 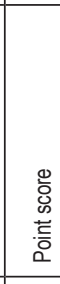 & $\frac{n}{t}$ & & 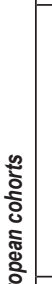 & 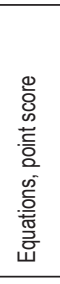 & 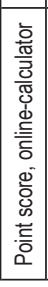 & 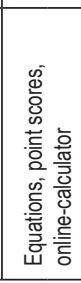 & 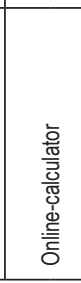 & 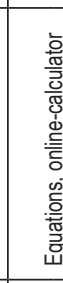 & & 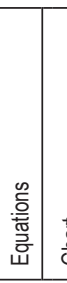 & & 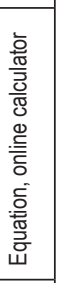 & 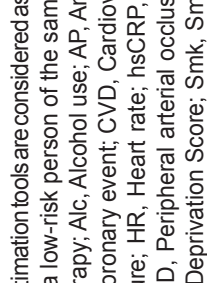 \\
\hline 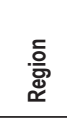 & 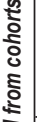 & & & 总 & & & $\begin{array}{l}\text { 을 } \\
\text { 올 }\end{array}$ & $\vec{u}$ & & 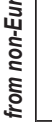 & & & 焉 & & 离 & & 离 & & 离 & \\
\hline 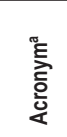 & 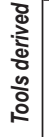 & & & 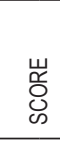 & & & $\begin{array}{l}\text { 岸 } \\
\text { 㟔 }\end{array}$ & 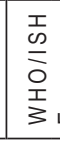 & & 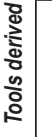 & & & 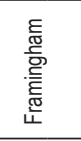 & & 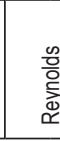 & & 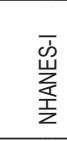 & & $\begin{array}{l}\infty \\
\text { 站 } \\
\text { d }\end{array}$ & $\frac{1}{2}$ \\
\hline
\end{tabular}


within 10 years (14). This score was derived from the data of about 8,000 participants aged 35-65 years of the entire PROCAM cohort and based only on the risk factors gender, age, smoking, blood pressure, and DM.

The first version of the PROCAM score was applied to men in France, Northern Ireland, England, and Italy, but showed a poor discrimination (7).

\section{Copenhagen Risk Score}

The first reference to the Copenhagen Risk Score was published in 2001 as a basis for the PRECARD ${ }^{\circledR}$ computer program (16). This tool was developed from data of almost 12,000 people aged 22-93 years from two population-based Danish studies. The computer program was designed for risk estimation of a myocardial infarction within 5,10 or 20 years, for younger persons also at the age of 60 years (although the follow-up was only 10 years). Besides the conventional risk factors it applies data on body height, weight, DM, and family history of MI. Unfortunately, the risk assessment with PRECARD ${ }^{\circledR}$ is not available online and the regression coefficients of the underlying equations are not published.

\section{CUORE}

The first CUORE equation presented in 2005 (17) estimates the risk of a coronary event in men. The tool uses conventional risk factors as well as the variables DM, antihypertensive treatment and family history of coronary heart disease (CHD). The 2007 published gender-specific equations (18) estimate the risk of a cardiovascular event and are based on twelve cohorts with more than 20,000 persons aged 35-69 years, about two third women. The tool uses the same risk factors except the family history of CHD. These equations are the basis for the online calculator (19) and for charts $(18,19)$ which are restricted for persons aged 40-69 years and use only the variables age, smoking, blood pressure, and cholesterol.

\section{Riskard}

The Riskard was published in 2005 (20) as multiple genderspecific equations for the software Riskard 2005 to assess the risk of a coronary event, the risk of a cerebrovascular event and the risk of a total cardiovascular event, each within 5, 10 and 15 years, as well as an equation underlying the risk charts Riskard 2005 for a cardiovascular event within 10 years. The software algorithms were derived from data of almost 16,000 persons aged 35-74 years. The equations for charts use only conventional risk factors and DM. The software algorithms additionally apply the variables body mass index (BMI) and heart rate. The corresponding website (21) enables an online calculation for the risk of a cardiovascular event within 10 years with Riskard 2005 using only conventional prognostic variables and also with Riskard 2009 which excluded data for individuals with DM from the derivation but additionally applies HDL-cholesterol levels and calculates a relative risk estimate.

\section{FINRISK}

FINRISK addresses the impact of the resting heart rate for the improvement of CVD prediction (22) and derived multiple equations for risk of fatal CVD event with and without the variable resting heart rate. The basic gender-specific equations contain conventional risk factors, in the simplified equations the laboratory parameters are replaced with the variable BMI. The equations were derived from data of the population-based cohort with $>30,000$ individuals aged $25-74$ years. The risk charts presented in the publication are based on simplified equations with the variable resting heart rate which was demonstrated to improve CVD prediction. Using the data of the FINRISK study charts to estimate the Risk Age based on all CVD events as well as based on only fatal CVD events were newly constructed (23). These charts use only conventional risk factors (analogues to SCORE) and are very similar for both underlying endpoints.

\section{ASSIGN}

The ASSIGN is known as the first risk-estimation tool, which takes into account the risk factor of social deprivation using the Scottish Index of Multiple Deprivation (SIMD) score. The tool was developed based on the data from two Scottish populationbased studies with $>13,000$ participants aged $30-74$ years and was published in 2007 as gender-specific equations to assess the risk of CVD (24). In addition to the variable social deprivation (derived from the postcode as a corresponding indicator) and conventional risk factors the equations use the variables family history of CVD and DM. The ASSIGN website enables an online assessment of the risk for CVD within 10 years using the updated version of the score (25).

The score showed a good discrimination for population of England and Wales as well as for primary care patients in Scotland and Northern Ireland (7).

\section{QRISK}

QRISK risk-estimation tools were derived from the data representative for the primary care of England and Wales and show the greatest number of participants currently used to construct the risk-estimation tool. The original QRISK and subsequent QRISK2 models to assess the risk for CVD based on more than million patients were published in 2007 and 2008, respectively $(26,27)$. Both models use conventional variables but also family history of CVD, BMI, antihypertensive treatment, and Townsend score, an indicator for material deprivation derived from the postal code (analogues to SIMD score). QRISK2 additionally incorporates the variables ethnicity, DM, chronic renal disease, atrial fibrillation, and rheumatic arthritis. QRISK was constructed excluding patients with DM, QRISK2 excluded patients treated with statins at baseline. In 2010, the new QRISK model to assess the lifetime CVD-risk which used the same variables as QRISK2 was presented (28).

The QRISK ${ }^{\circledR}$ websites enable to calculate online the risk of CVD within 10 years for 25-84 years old persons with QRISK2 providing the corresponding relative risk and Heart Age (29) as well as the CVD-risk at any age up to 95 years using the QRISKLifetime (30). The regression coefficients of the QRISK2 are being updated using the new data analyses.

QRISK and QRISK2 showed a relatively good discrimination for primary care patients in Scotland and Northern Ireland (7).

\section{CAREMA}

CAREMA equation was constructed to re-estimate the SCORE function for the Netherlands using individual data (31). The model applies analogues to SCORE only conventional risk factors but separate total and HDL-cholesterol levels (instead of their ratio). 
The equation to estimate the risk of fatal and non-fatal CHD events within 10 years is based on data for $\approx 20,000$ participants aged $20-59$ years of the population-based study conducted in the Netherlands.

\section{Risk-estimation Tools Derived from Cohorts of Sev- eral European Countries}

\section{SCORE}

The SCORE was developed by the European Society of Cardiology and was published in 2003 as gender-specific equations and charts (32). The equations were derived from data of more than 200,000 participants aged 19-80 years from twelve European cohort studies, mainly population-based cohorts (32). Using derived equations the charts for risk of fatal CVD within 10 years were constructed separately for countries with a high or low CVD-risk. Published risk charts incorporate only conventional variables and enable risk estimation for persons aged 40-65 years of each region either with total cholesterol or with the ratio of total cholesterol to HDL-cholesterol. The SCORE charts presented on the corresponding website are based on total cholesterol and offer also relative risk estimation (33).

The website also enables an interactive risk calculation using the program HeartScore ${ }^{\circledR}$ for countries with high or low CVD-risk or specific versions for 15 European countries in 17 languages (for 8 countries after recalibration). Alternatively, the online risk assessment may be performed with a simplified tool using only body height and weight instead of blood pressure and cholesterol measures (33). Determining the risk is completed with management advice.

In 2010, the special conversion tables and charts for high-risk and low-risk countries to assess the Vascular Age of a person were presented (34). They used the same variables as the tool for absolute risk and show very similar estimates for both risk regions. Another chart to assess Cardiovascular Risk Age with the same risk factors was published in 2012 (23).

SCORE has been applied to Spanish and Dutch populations and showed a very good discrimination (7).

\section{DECODE}

The tool DECODE comprises gender-specific point scores to estimate the risk of fatal CVD within 5 or 10 years focusing on event prediction over glucose metabolism (35). The equation is based on data for more than 25,000 participants aged 19-80 years of 14 cohort studies from eight European countries, mainly population-based cohorts. In addition to the conventional prognostic variables, data on DM (or blood glucose) and country-specific coefficients are used.

\section{WHO/ISH Europe}

The originally intended users of the risk-estimation tool developed by the World Health Organization and the International Society of Hypertension (WHO/ISH) are countries without available resources to derive a population-specific tool, generally low-income and middle-income countries (36). Corresponding risk charts for 14 sub-regions of the world to estimate the 10year risk of a cardiovascular event for persons aged 30-79 years are downloadable (37). Based on their mortality all European countries are grouped into three sub-regions. For each sub-region gender-specific risk charts using conventional prognostic risk factors and variable DM as well as simplified risk charts without variable total cholesterol are presented.

Using a modelling approach, the construction of the risk charts is based on information from the studies on the regional distribution of the risk factors, on the relative risks of the risk factors as well as on the corresponding population-level estimate of absolute risks for cardiovascular events (36).

\section{Risk-estimation Tools Derived from Non-European Cohorts}

\section{Framingham Tools}

The first world-wide known risk-estimation tool was constructed based on the analysis of the data of a relatively small cohort of about 6,000 residents of Framingham, USA. For a long time most commonly used were the equations of Anderson et al. (38) and derived from this equation points scores for the estimation of the 5-year and 10-year risks for CHD (39). Well-known are also several other derivations from these equations (40-47). Moreover, data from the Framingham cohort were used for the risk-estimation tool for stroke $(48,49)$ and for intermittent claudication (50), published in the 1990s.

Subsequently constructed risk-estimation tools of the Framingham group are based on new derivations of the risk coefficients. The tool of Wilson et al. (51) estimates the 10-year risk of CHD, the tool of Adult Treatment Panel III (ATP III) (52) the 10-year risk of a coronary event and the tool of D'Agostino et al. (53) the 10-year risk of CVD. All these instruments include conventional prognostic parameters for risk estimation. Wilson et al. (51) and D'Agostino et al. (53) apply additionally the variable DM, whereas ATP III (52) was envisaged only for persons without DM. ATP III (52) and D'Agostino et al. (53) differentiate between treated and non-treated systolic blood pressure. D'Agostino et al. (53) also constructed a simplified model for CVDrisk assessment replacing cholesterol parameters with BMI as well as point scores to estimate Heart Age/Vascular Age. The latest, in 2009 published instrument of Pencina et al. (54) estimates the risk of a cardiovascular event and the risk of CVD within 30 years. It is derived from the data for $>4,000$ individuals aged 20-60 years. The risk estimation is based besides conventional risk factors on the variables DM and antihypertensive treatment. In a simplified model cholesterol is replaced with BMI.

The website of the Framingham Heart Study (55) presents all above mentioned risk-estimation tools and enables an online assessment of the 10-year risk of a coronary event, the 10-year risk of CVD as well as the 30-year risks of CVD and a cardiovascular event. The interactive risk assessment, except for a coronary event, can be performed using lipid levels or body-mass index. Besides the estimated individual's risk the calculator provides also the normal and optimal risk levels. The corresponding Excel spreadsheets are also downloadable.

Risk-estimation tools based on the equations of Anderson et al. $(38,39)$ were applied in different European studies, particularly on various British, but also on German, Danish and Dutch populations. The tool of Wilson et al. (51) was used on men from Northern Ireland, France, Germany, and Italy and also on a nondiabetic population of Spain. The tool of ATP III (52) was applied to male population of Germany and UK. The discrimination in the studies ranged from poor to good values (7). 


\section{Reynolds Risk Score}

The development of the Reynolds Risk Score was aimed to use several new risk factors associated with increased risk for CVD such as metabolism-related variables (e.g. lipoprotein A), inflammatory markers (C-reactive protein), markers of glucose metabolism, plasma creatinine and homocystein values.

Primarily, several equations were published in 2007 to calculate the risk of a cardiovascular event based on the data of an occupational cohort of more than 16,000 U.S. women (56). The simplified risk-estimation equation (namely Reynolds Risk Score) uses in addition to conventional risk factors and family history of MI the variables C-reactive protein and hemoglobin A1c. The additionally investigated best-fitting equation also included the variables apolipoprotein AI, apolipoprotein B-100 and lipoprotein (a). The Reynolds Risk Score equation for men was published in 2008 and based on the data of an occupational cohort of almost 11,000 U.S. non-diabetic men (57). The riskestimation tool has the same endpoint and uses the same risk factors, except hemoglobin A1c, compared to the published equations for women.

The website (58) of the Reynolds Risk Score enables to estimate the 10-year risk of a cardiovascular event at current age as well as at next age-decades for non-diabetic persons aged 45-80 years using conventional risk factors, family history of MI and the variable $\mathrm{C}$-reactive protein.

\section{Other Risk-estimation Tools Derived from Non-European Cohorts}

The Risk Chart based on the U.S. NHANES-I cohort of $\approx 6,000$ persons (59) was primarily constructed for developing countries. The estimation of the 5-year CVD-risk for individuals aged 35-74 years does not require laboratory tests, using only data on gender, age, smoking, DM, systolic blood pressure, and BMI. The article also provides regression coefficients for equations based on BMI or on total cholesterol with additional variable antihypertensive treatment.

The development of the U.S. risk-estimation tool GVRS (60) was aimed to improve risk assessment using behavioural and anthropometric parameters. The tool uses in addition to the conventional risk factors and variables blood glucose, peripheral vascular disease and antihypertensive treatment data on ethnicity, waist circumference, alcohol consumption and physical activity. The website enables to estimate the 5-year risk and the 10-year risk for a cardiovascular event (61).

In addition to the already described risk-estimation tools derived from the U.S. populations several instruments were published based on the data from Asian populations, the Japanese NIPPON DATA80 (62) and two Chinese prognostic tools (63, 64). However, these instruments are not relevant for the general European population due to ethnic variability in the CVD-risk.

\section{DISCUSSION}

\section{Clinical Usefulness of Various Risk-estimation Tools}

The decision about the clinical usefulness of a risk-estimation tool may be based on its prognostic accuracy. When a good calibration is not achieved an instrument should be recalibrated.
A perfect discrimination (AUROC value of 1.0) of a risk-estimation tool for CVD is not possible, even the internal validation for various tools did not achieve the AUROC value of 0.9 . In addition, the performance criteria for the discrimination are generally not established. For example, NICE refers AUROC values from 0.9 to 1.0 as excellent, from 0.8 to 0.9 as good, from 0.7 to 0.8 as sufficient, from 0.6 to 0.7 as weak, and from 0.5 to 0.6 as very weak discrimination (6). In some publications AUROC values even from 0.66 to 0.88 are considered good (4), over 0.75 as very good (8) or high (9), over 0.82 as excellent (5) discrimination. The AUROC value of 0.75 was proposed as the minimum requirement for a risk-estimation tool to be applied (8) and the most tools attain this value.

When the tool predicts the development of clinical event accurately, the general conclusion may be derived that a change in the modifiable risk factors reduces the risk of this event. Whether such conclusions are valid for all risk factors and particularly in the predicted magnitude with regard to CVD is questionable (2). Should the modifiable risks be reduced to the average, "ideal" or even lower values of the corresponding age and gender group $(2,8)$ ? Moreover, although there is evidence for reduction of cardiovascular events by modifying the single risk factors such as cholesterol or arterial blood pressure, no reliable evidence from randomised controlled trials exists for the events reduction using a risk-estimation tool (9).

Whether more easily standardised (and, therefore, allowing better recalibration) "hard" endpoints or clinical more relevant "soft" outcomes should be favoured for the risk estimation remains debatable. Generally, since the goal of primary prevention is the avoidance of all vascular diseases at their earlier stages, the CVDrisk assessment is preferable (9). In some cases, a therapeutic approach for different patient groups may be based on the risk assessment of different outcomes, e.g. aspirin administered to men at risk of CHD and to women at risk of stroke (65).

Choosing a risk-estimation tool depends on the accessibility to patient's data (i.e. laboratory measurements). The conventional variables are generally sufficient. Since the variables gender and age alone are responsible for the AUROC of up to 0.7 (4), the inclusion of each additional risk factor leads to an ever smaller improvement in the predictive ability of the model. Moreover, simple (but accurate) models may be more generalizable to other settings, because they reflect essential mechanisms that function across different populations (10). In patients with borderline risk additional non-invasive tests (e.g. ankle-brachial index) may be applied $(4,5)$, assumed that they have a high net reclassification index. Since the risk factors may change over time (due to changes in life-style, environment, etc.) the periodical update of the model would ensure more accurate prediction (10).

Instruments for assessing an intermediate-term absolute risk are mainly relevant to select high-risk persons for aggressive risk reduction. The concept of a lifetime risk may be rather important for policy-makers to support the prevention activity including the allocation of resources. The Relative Risk charts and Cardiovascular Age equivalents are thought to identify young people with increased risk factors but low risk in the intermediate-term follow-up solely due to the young age (8). For elderly people, instruments which consider the effect of age on risk factors using interaction variables or specially constructed risk-estimation tools (out of scope of this review) are preferable. 
Finally, it is also important to communicate the risk assessment to individuals in a understandable and motivating way (8). Useful approaches are providing absolute levels of cardiovascular risk rather than risk categories and presenting graphics instead of just numbers (66). Especially the use of the cardiovascular age equivalences is considered by patients to be well understandable and motivating (8). Promising results showed the integration of the risk-estimation tool into the medical computer software (67).

\section{CONCLUSION}

Which risk-estimation tool for primary prevention of CVD should be used in a European population? From clinical perspective, preferable seems to be instruments contemporary developed for this population, which use easily accessible measures and show a high discriminating ability. Instruments, restricting risk-estimation to certain cardiovascular events, high-accuracy recalibrated risk-estimation tools or tools derived from European populations with similar risk factors distribution and CVD-incidence can be used as the second choice. In younger people, calculating the relative risk or cardiovascular age equivalence measures may be of more benefit. The integration of risk-estimation tools in the medical computer software is promising.

\section{Conflicts of Interests}

None declared

\section{Funding}

This research received no specific grant from any funding agency in the public, commercial, or not-for-profit sectors.

\section{REFERENCES}

1. Gohlke H. Risk stratification with difference scoring systems. ESC SCORE, Framingham risk score, PROCAM, and CARRISMA. Clin Res Cardiol. 2006;1 Suppl 2:139-48. (In German.)

2. Gohlke H, von Schacky C. Total risk for cardiovascular disease. At what point is medical prophylactic medication useful?. Z Kardiol. 2005;94 Suppl 3:III/6-10. (In German.)

3. Sullivan LM, Massaro JM, D'Agostino RB Sr. Presentation of multivariate data for clinical use: The Framingham Study risk score functions. Stat Med. 2004 May 30;23(10):1631-60.

4. Cooney MT, Dudina AL, Graham IM. Value and limitations of existing scores for the assessment of cardiovascular risk: a review for clinicians. J Am Coll Cardiol. 2009 Sep 29;54(14):1209-27.

5. Berger JS, Jordan CO, Lloyd-Jones D, Blumenthal RS. Screening for cardiovascular risk in asymptomatic patients. J Am Coll Cardiol. 2010 Mar 23;55(12):1169-77.

6. Beswick AD, Brindle P, Fahey T, Ebrahim S. A systematic review of risk scoring methods and clinical decision aids used in the primary prevention of coronary heart disease. NICE clinical guidelines, no. 67S. London: Royal College of General Practitioners; 2008.

7. Gorenoi V, Schönermark MP, Hagen A. Assessments tools for risk prediction of cardiovascular diseases. HTA-Bericht. 2009;90:1-73. (In German.)

8. Grover SA, Lowensteyn I. The challenges and benefits of cardiovascular risk assessment in clinical practice. Can J Cardiol. 2011 JulAug;27(4):481-7.

9. Cooney MT, Dudina A, D'Agostino R, Graham IM. Cardiovascular riskestimation systems in primary prevention: do they differ? Do they make a difference? Can we see the future? Circulation. 2010 Jul 20;122(3):300-10.

10. Prieto-Merino D, Pocock SJ. The science of risk models. Eur J Prev Cardiol. 2012 Aug;19(2 Suppl):7-13.

11. Justice AC, Covinsky KE, Berlin JA. Assessing the generalizability of prognostic information. Ann Intern Med. 1999 Mar 16;130(6):515-24.
12. D'Agostino RB Sr, Grundy S, Sullivan LM, Wilson P; CHD Risk Prediction Group. Validation of the Framingham coronary heart disease prediction scores: results of a multiple ethnic groups investigation. JAMA. 2001 Jul 11;286(2):180-7.

13. Assmann G, Cullen P, Schulte H. Simple scoring scheme for calculating the risk of acute coronary events based on the 10-year follow-up of the prospective cardiovascular Münster (PROCAM) study. Circulation. 2002 Jan 22;105(3):310-5.

14. Assmann G, Schulte H, Cullen P, Seedorf U. Assessing risk of myocardial infarction and stroke: new data from the Prospective Cardiovascular Münster (PROCAM) study. Eur J Clin Invest. 2007 Dec;37(12):925-32.

15. International Task Force for Prevention of Coronary Heart Disease. Coronary risk assessment [Internet]. International Task Force for Prevention of Coronary Heart Disease; 2010 [cited 2013 Apr 20]. Available from: http://www.chd-taskforce.com/coronary_risk_assessment.html.

16. Thomsen TF, Davidsen M, Ibsen H, Jørgensen T, Jensen G, Borch-Johnsen $\mathrm{K}$. A new method for $\mathrm{CHD}$ prediction and prevention based on regional risk scores and randomized clinical trials; PRECARD and the Copenhagen Risk Score. J Cardiovasc Risk. 2001 Oct;8(5):291-7.

17. Ferrario M, Chiodini P, Chambless LE, Cesana G, Vanuzzo D, Panico S, et al.; CUORE Project Research Group. Prediction of coronary events in a low incidence population. Assessing accuracy of the CUORE Cohort Study prediction equation. Int J Epidemiol. 2005 Apr;34(2):413-21.

18. Giampaoli S, Palmieri L, Donfrancesco C, Panico S, Vanuzzo D, Pilotto $\mathrm{L}$, et al. Cardiovascular risk assessment in Italy: the CUORE Project risk score and risk chart. Ital J Public Health. 2007;4(2):102-9.

19. CUORE Project. Calculating the individual risk score [Internet]. Rome: Cnesps - Istituto Superiore di Sanità; 2009 [cited 2013 Apr 20]. Available from: http://www.cuore.iss.it/sopra/calc-rischio_en.asp.

20. Menotti A, Lanti M, Agabiti-Rosei E, Carratelli L, Cavera G, Dormi A, et al. Riskard 2005. New tools for prediction of cardiovascular disease risk derived from Italian population studies. Nutr Metab Cardiovasc Dis. 2005 Dec;15(6):426-40.

21. Centre Against Myocardial Infarction. Riskard 2009 [Internet]. Rome: Centre Against Myocardial Infarction; 2009 [cited 2013 Apr 20]. Available from: http://www.centrolottainfarto.org/riskard-2009. (In Italian.)

22. Cooney MT, Vartiainen E, Laatikainen T, Joulevi A, Dudina A, Graham I. Simplifying cardiovascular risk estimation using resting heart rate. Eur Heart J. 2010 Sep;31(17):2141-7.

23. Cooney MT, Vartiainen E, Laatikainen T, De Bacquer D, McGorrian C, Dudina A, et al.; SCORE and FINRISK investigators. Cardiovascular risk age: concepts and practicalities. Heart. 2012 Jun;98(12):941-6.

24. Woodward M, Brindle P, Tunstall-Pedoe H; SIGN group on risk estimation. Adding social deprivation and family history to cardiovascular risk assessment: the ASSIGN score from the Scottish Heart Health Extended Cohort (SHHEC). Heart. 2007 Feb;93(2):172-6.

25. Assign score. Prioritising prevention of cardiovascular disease [Internet]. Assign Score; 2013 [cited 2013 Apr 20]. Available from: http://assignscore.com/.

26. Hippisley-Cox J, Coupland C, Vinogradova Y, Robson J, May M, Brindle P. Derivation and validation of QRISK, a new cardiovascular disease risk score for the United Kingdom: prospective open cohort study. BMJ. 2007 Jul 21;335(7611):136.

27. Hippisley-Cox J, Coupland C, Vinogradova Y, Robson J, Minhas R, Sheikh A, et al. Predicting cardiovascular risk in England and Wales: prospective derivation and validation of QRISK2. BMJ. 2008 Jun 28;336(7659):1475-82.

28. Hippisley-Cox J, Coupland C, Robson J, Brindle P. Derivation, validation, and evaluation of a new QRISK model to estimate lifetime risk of cardiovascular disease: cohort study using QResearch database. BMJ. 2010 Dec 9;341:c6624.

29. QRISK $® 2-2013$ cardiovascular disease risk calculator [Internet]. ClinRisk; 2013 [cited 2013 Apr 21]. Available from: http://www.qrisk.org/.

30. QRISK $($-lifetime cardiovascular risk calculator [Internet]. ClinRisk; 2012 [cited 2013 Apr 21]. Available from: http://qrisk.org/lifetime.

31. Merry AH, Boer JM, Schouten LJ, Ambergen T, Steyerberg EW, Feskens EJ, et al. Risk prediction of incident coronary heart disease in The Netherlands: re-estimation and improvement of the SCORE risk function. Eur J Prev Cardiol. 2012 Aug;19(4):840-8.

32. Conroy RM, Pyörälä K, Fitzgerald AP, Sans S, Menotti A, De Backer $\mathrm{G}$, et al.; SCORE project group. Estimation of ten-year risk of fatal cardiovascular disease in Europe: the SCORE project. Eur Heart J. 2003 Jun;24(11):987-1003.

33. European Society of Cardiology. HeartScore [Internet]. Sophia Antipolis: ESC; 2010 [cited 2013 Apr 20]. Available from: http://www.heartscore. org/Pages/online.aspx. 
34. Cuende JI, Cuende N, Calaveras-Lagartos J. How to calculate vascular age with the SCORE project scales: a new method of cardiovascular risk evaluation. Eur Heart J. 2010 Oct;31(19):2351-8.

35. Balkau B, Hu G, Qiao Q, Tuomilehto J, Borch-Johnsen K, Pyörälä K; DECODE Study Group; European Diabetes Epidemiology Group. Prediction of the risk of cardiovascular mortality using a score that includes glucose as a risk factor. The DECODE Study. Diabetologia. 2004 Dec;47(12):2118-28.

36. Mendis S, Lindholm LH, Mancia G, Whitworth J, Alderman M, Lim S, et al. World Health Organization (WHO) and International Society of Hypertension (ISH) risk prediction charts: assessment of cardiovascular risk for prevention and control of cardiovascular disease in low and middle-income countries. J Hypertens. 2007 Aug;25(8):1578-82.

37. World Health Organization. Cardiovascular disease. WHO/ISH cardiovascular risk prediction charts [Internet]. Geneva: WHO; 2007 [cited 2012 Nov 22]. Available from: http://www.who.int/cardiovascular diseases/ guidelines/Chart_predictions/en/index.html.

38. Anderson KM, Odell PM, Wilson PW, Kannel WB. Cardiovascular disease risk profiles. Am Heart J. 1991 Jan;121(1 Pt 2):293-8.

39. Anderson KM, Wilson PW, Odell PM, Kannel WB. An updated coronary risk profile. A statement for health professionals. Circulation. 1991 Jan;83(1):356-62.

40. Pyörälä K, De Backer G, Graham I, Poole-Wilson P, Wood D. Prevention of coronary heart disease in clinical practice. Recommendations of the Task Force of the European Society of Cardiology, European Atherosclerosis Society and European Society of Hypertension. Eur Heart J. 1994 Oct;15(10):1300-31.

41. Wood D, De Backer G, Faergeman O, Graham I, Mancia G, Pyörälä K Prevention of coronary heart disease in clinical practice: recommendations of the Second Joint Task Force of European and other Societies on Coronary Prevention. Atherosclerosis. 1998 Oct;140(2):199-270.

42. British Cardiac Society; British Hyperlipidaemia Association; British Hypertension Society; endorsed by the British Diabetic Association. Joint British recommendations on prevention of coronary heart disease in clinical practice.. Heart. 1998 Dec;80 Suppl 2:S1-29.

43. British Cardiac Society; British Hypertension Society; Diabetes UK; HEART UK; Primary Care Cardiovascular Society; Stroke Association. JBS 2: Joint British Societies' guidelines on prevention of cardiovascular disease in clinical practice. Heart. 2005 Dec;91 Suppl 5:v1-52.

44. Jackson R. Updated New Zealand cardiovascular disease risk-benefit prediction guide. BMJ. 2000 Mar 11;320(7236):709-10.

45. Jackson R, Barham P, Bills J, Birch T, McLennan L, MacMahon S, et al. Management of raised blood pressure in New Zealand: a discussion document. BMJ. 1993 Jul 10;307(6896):107-10.

46. NICE. Lipid Modification: cardiovascular risk assessment and the modification of blood lipids for the primary and secondary prevention of cardiovascular disease [Internet]. London: National Institute for Health and Care Excellence; 2008 [cited 2008 Sep 9]. Available from: http:// www.nice.org.uk/CG067.

47. McCormack JP, Levine M, Rangno RE. Primary prevention of heart disease and stroke: a simplified approach to estimating risk of events and making drug treatment decisions. CMAJ. 1997 Aug 15;157(4):422-8.

48. Wolf PA, D'Agostino RB, Belanger AJ, Kannel WB. Probability of stroke: a risk profile from the Framingham Study. Stroke. 1991 Mar;22(3):312-8.

49. D'Agostino RB, Wolf PA, Belanger AJ, Kannel WB. Stroke risk profile: adjustment for antihypertensive medication. The Framingham Study. Stroke. 1994 Jan;25(1):40-3.

50. Murabito JM, D'Agostino RB, Silbershatz H, Wilson WF. Intermittent claudication. A risk profile from The Framingham Heart Study. Circulation. 1997 Jul 1;96(1):44-9.

51. Wilson PW, D'Agostino RB, Levy D, Belanger AM, Silbershatz H, Kannel WB. Prediction of coronary heart disease using risk factor categories. Circulation. 1998 May 12;97(18):1837-47.
52. Expert Panel on Detection, Evaluation, and Treatment of High Blood Cholesterol in Adults. Executive Summary of The Third Report of The National Cholesterol Education Program (NCEP) Expert Panel on Detection, Evaluation, And Treatment of High Blood Cholesterol In Adults (Adult Treatment Panel III). JAMA. 2001 May 16;285(19):2486-97.

53. D'Agostino RB Sr, Vasan RS, Pencina MJ, Wolf PA, Cobain M, Massaro $\mathrm{JM}$, et al. General cardiovascular risk profile for use in primary care: the Framingham Heart Study. Circulation. 2008 Feb 12;117(6):743-53.

54. Pencina MJ, D'Agostino RB Sr, Larson MG, Massaro JM, Vasan RS. Predicting the 30-year risk of cardiovascular disease: the framingham heart study. Circulation. 2009 Jun 23;119(24):3078-84.

55. Framingham Heart Study. Risk score profiles [Internet]. Framingham: Framingham Heart Study; 2012 [cited 2013 Apr 20]. Available from: http://www.framinghamheartstudy.org/risk/index.html.

56. Ridker PM, Buring JE, Rifai N, Cook NR. Development and validation of improved algorithms for the assessment of global cardiovascular risk in women: the Reynolds Risk Score. JAMA. 2007 Feb 14;297(6):611-9.

57. Ridker PM, Paynter NP, Rifai N, Gaziano JM, Cook NR. C-reactive protein and parental history improve global cardiovascular risk prediction: the Reynolds Risk Score for men. Circulation. 2008 Nov 25;118(22):2243-51, $4 \mathrm{p}$ following 2251

58. Reynolds Risk Score [Internet]. Reynolds Risk Score; 2012 [cited 2013 Apr 20]. Available from: http://www.reynoldsriskscore.org/.

59. Gaziano TA, Young CR, Fitzmaurice G, Atwood S, Gaziano JM. Laboratory-based versus non-laboratory-based method for assessment of cardiovascular disease risk: the NHANES I Follow-up Study cohort. Lancet. 2008 Mar 15;371(9616):923-31.

60. Sacco RL, Khatri M, Rundek T, Xu Q, Gardener H, Boden-Albala B, et al. Improving global vascular risk prediction with behavioral and anthropometric factors. The multiethnic NOMAS (Northern Manhattan Cohort Study). J Am Coll Cardiol. 2009 Dec 8;54(24):2303-11.

61. University of Miami, Miller School of Medicine, Department of Neurology. Global Vascular Risk Score Calculator [Internet]. Miami: University of Miami; 2008 [cited 2013 Apr 20]. Available from: http://neurology. med.miami.edu/gvr/.

62. NIPPON DATA 80 Research Group. Risk assessment chart for death from cardiovascular disease based on a 19-year follow-up study of a Japanese representative population. Circ J. 2006 Oct;70(10):1249-55

63. Zhang XF, Attia J, D'Este C, Yu XH, Wu XG. A risk score predicted coronary heart disease and stroke in a Chinese cohort. J Clin Epidemiol. 2005 Sep;58(9):951-8

64. Kang GD, Guo L, Guo ZR, Hu XS, Wu M, Yang HT. Continuous metabolic syndrome risk score for predicting cardiovascular disease in the Chinese population. Asia Pac J Clin Nutr. 2012;21(1):88-96.

65. US Preventive Services Task Force. Aspirin for the prevention of cardiovascular disease: U.S. Preventive Services Task Force recommendation statement. Ann Intern Med. 2009 Mar 17;150(6):396-404.

66. Waldron CA, van der Weijden T, Ludt S, Gallacher J, Elwyn G. What are effective strategies to communicate cardiovascular risk information to patients? A systematic review. Patient Educ Couns. 2011 Feb;82(2):16981.

67. Wells S, Furness S, Rafter N, Horn E, Whittaker R, Stewart A, et al. Integrated electronic decision support increases cardiovascular disease risk assessment four fold in routine primary care practice. Eur J Cardiovasc Prev Rehabil. 2008 Apr;15(2):173-8. 